\title{
$-$ \\ How we do it: robotic-assisted distal ureterectomy with ureteral reimplantation
}

\author{
Christopher Pulford ${ }^{1}$, Kevin Keating 2, Matthew Rohloff ${ }^{2}$, David Peifer ${ }^{2}$, Richard Eames ${ }^{2}$, Thomas \\ Maatman ${ }^{2}$ \\ ${ }^{1}$ Arizona College of Osteopathic Medicine, Midwestern University, AZ, USA; ${ }^{2}$ Department of Urology, \\ Metro Health, University of Michigan, MI, USA
}

\section{ABSTRACT}

Background: High risk upper tract urothelial carcinoma (UTUC) is typically managed with radical nephroureterectomy, however, renal preservation can be attempted when UTUC is localized to the distal ureter in the presence of chronic kidney disease (1-3). Distal ureterectomy is typically managed with a ureteral reimplantation and psoas hitch in order to maintain urothelial continuity, to avoid comprising the contralateral ureter, and reducing risk of chronic urinary tract infections and electrolyte abnormalities (4). We present our case of distal ureteral UTUC managed robotically with a distal ureterectomy with ureteral reimplantation.

Technique and Follow-Up: Initially, an Orandi needle on a resectoscope circumscribed the left ureteral orifice. Next, robotically, the retroperitoneum was exposed and a left sided pelvic lymphadenectomy was completed. The left ureter was mobilized and the diseased ureteral segment was transected. The mobilized bladder was sutured to psoas fascia. After a cystotomy, the ureter was re-anastomosed to the bladder. The patient was discharged on postoperative day three and re-evaluated one week later with a cystogram. Final pathology was downgraded to non-invasive low-grade papillary urothelial carcinoma with negative lymph nodes and margins.

Conclusion: High risk UTUC localized to the distal ureter in the setting of chronic kidney disease can be managed with a distal ureterectomy (3). Robotic distal ureterectomy with ureteral reimplantation can be assisted by an Orandi needle to achieve negative margins. Utilizing a robotic technique can offer challenges with the ureteral spatulation and reanastomosis (5-7). By fixating the ureter to the bladder prior to reanastomosis, our technique offers a solution for these difficulties.

\section{SOURCE OF WORK}

All work is original from TM and Metro Health - University of Michigan.

Authors have received and archived patient consent for video recording/publication in advance of video recording procedure. 


\section{CONFLICT OF INTEREST}

None declared.

\section{REFERENCES}

1. Xylinas E, Rink M, Cha EK, Clozel T, Lee RK, Fajkovic H, et al. Impact of distal ureter management on oncologic outcomes following radical nephroureterectomy for upper tract urothelial carcinoma. Eur Urol. 2014; 65:210-7.

2. Yakoubi R, Colin P, Seisen T, Léon P, Nison L, Bozzini G, et al. Radical nephroureterectomy versus endoscopic procedures for the treatment of localised upper tract urothelial carcinoma: a meta-analysis and a systematic review of current evidence from comparative studies. Eur J Surg Oncol. 2014; 40:1629-34.

3. Bagrodia A, Kuehhas FE, Gayed BA, Wood CG, Raman JD, Kapur $P$, et al. Comparative analysis of oncologic outcomes of partial ureterectomy vs radical nephroureterectomy in upper tract urothelial carcinoma. Urology. 2013; 81:972-7.
4. Ahn M, Loughlin KR. Psoas hitch ureteral reimplantation in adults--analysis of a modified technique and timing of repair. Urology. 2001; 58:184-7.

5. Uberoi J, Harnisch B, Sethi AS, Babayan RK, Wang DS. Robot-assisted laparoscopic distal ureterectomy and ureteral reimplantation with psoas hitch. J Endourol. 2007; 21:368-73; discussion 372-3.

6. Giannakopoulos S, Efthimiou I, Bantis A, Kalaitzis C, Touloupidis S. A simplified technique for ureteral spatulation in laparoscopic pyeloplasty. J Endourol. 2012; 26:618-20.

7. Yang C, Jones L, Rivera ME, Verlee GT, Deane LA. Roboticassisted ureteral reimplantation with Boari flap and psoas hitch: a single-institution experience. J Laparoendosc Adv Surg Tech A. $2011 ; 21: 829-33$.
Submitted for publication:

March 17, 2021

Accepted after revision:

March 24, 2021

Published as Ahead of Print: June 25, 2021
Correspondence address: Christopher Pulford, MD Arizona College of Osteopathic Medicine, Midwestern University 19555 N. 59th Ave. Glendale AZ 85308, AZ, USA E-mail: cpulford98@midwestern.edu

\section{ARTICLE INFO}

Christopher

https://orcid.org/0000-0002-2068-7714

Available at: http://www.intbrazjurol.com.br/video-section/20210207_Pulford_et_al Int Braz J Urol. 2021; 47 (Video \#20): 1277-8 